\title{
Chromosome Analysis of Experimental Rat Glial Tumor(1)-Correlation of chromosome changes between glial tumors and fetal brain tissue of rats after a transplacental exposure to ethylnitrosourea
}

\author{
Makoto TAnaka and Satoshi Matsumoto \\ Neurological Surgery, School of Medicine, \\ Kobe University
}

\begin{abstract}
Summary
Chromosomal constitution of 7 rat glial tumors induced by methylnitrosourea (MNU) and ethylnitrosourea (ENU) was investigated. Cells from rat glial tumors showed preferentially complete monosomy for \#3 chromosomes and partial monosomy for \#2 chromosomes. Numerical and morphological changes in \#11 and \#12 chromosomes were also observed. These chromosome aberrations have no relation with histological classification of experimental rat gial tumors. One \# 3 chromosome missing in neolplastic glial tumors was constantly observed through a long term culture and had no relation with the appearance of marker chromosome. These chromosome changes were compared with the preferential involvement of \#1 and 2 chromosomes in fetal brain cells of rats shortly after a transplacental administration of ENU.
\end{abstract}

Key words:

rat glial tumor, Chemical carcinogen, cell culturc, chromosome.

\section{Introduction}

The transplacental induction of tumors by methylnitrosourea (MNU) and ethylnitrosourea (ENU) in the nervous system is well known and was analysed sufficiently statistically. $4.8 .11,21.24$ )

The mechanism of transplacental carcinogenic action of the nitroso compounds is thought to be related to alkylation of some cellular component. ${ }^{3.5 .7 .8)}$ The fetal brain of the rat, however, showed destruction of cells in the subepedymal zones shortly after a transplacental administration of $\mathrm{ENU}^{23)}$ and it is impossible to obtain any histological clues for latent carcinogenic transformation from acute toxic lesion in the subependymal zones. If transplacental carcinogenecity is consistent with the alkylation of DNA, these DNA changes due to the alkylation may show some chromosome changes which can be detectable with conventional or banding method. If so, these chromosome changes must be permanently observed in cells of the rat brain after a transplacental administration of the nit- roso compounds as a carcinogenic transformation later in life and transmit in tumor cells in the nervous system.

From this point of view, chromosome abnormality in cells from 7 rat glial tumors were statistically analysed and these changes were compared with preferential chromosome damages caused by toxical activity of ENU.

This paper shows the possibility of a target chromosome of the carcinogenecity in the rat glial tumors induced by a transplacental administration of ENU or repeated injections of MNU.

\section{Materials and Methods}

\section{A) Experimentally induced glial tumors}

Pregnant SD-JCL rats received a single intraperitoneal injection of $50 \mathrm{mg} / \mathrm{kg}$ of ENU on the 17th day of gestation. Exceptionally, a glial tumor in Case 1 was induced by repeated administrations of MNU and Diethylstilbestrol (Depot Oestronom ${ }^{\mathrm{R}}$ ). Details were described in a 
previous paper. ${ }^{11}$ Rats were examined periodically. When the animals showed marked neurological signs, they were sacrificed with chloroform inhalation and the tumor in the brain was taken out, washed and divided into two parts; one part of the tumor was fixed for a light microscope, and the other one was dissected with scissors and cell suspension was made with pippetting. The suspension was diluted with Eagle's MEM supplemented with $10 \%$ fetal bovine serum, $100 \mathrm{U} / \mathrm{ml}$ of penicillin and $50 \mathrm{mcg} / \mathrm{ml}$ of amphotericin B. The diluted cell suspension was placed in petri dishes and incubated in humidified atmosphere of $5 \% \mathrm{CO}_{2}$ and $95 \%$ air. Subculture and chromosome analysis were periodically made.

\section{B) Chromosome staining of the tumor cells}

The cultrured tumor cells were incubated in medium containing $0.02 \gamma$ colcemid per $\mathrm{ml}$ of medium for 2 to 5 hours.

Thereafter, the cells were separated from the bottom of petri dishes by treatment with $0.1 \%$ natrium citrate solution for 20 minutes at $37^{\circ} \mathrm{C}$, and fixed in a $1: 3$ solution of glacial acetic acid and methanol. The fixed cell suspension was scattered on slide glasses with a Pasteur pippete. The slide glasses were dried by air for 24 hours, and then stained with conventional Giemsa stain or the G-banding method by A.T. Sumner. ${ }^{20)}$ Fifty metaphases in each case were examined under a light microscope for the counting of chromosome number and for karyotype analysis.

\section{Results:}

A) Distribution of chromosome number in cells from 7 rat glial tumors

The histological diagnosis of the 7 rat tumors used for chromosome analysis was summarized in Table 1. The tumor in Case 1 was obtained from the brain of a BD-IX rat by repeated injections of $\mathrm{MNU}$ and Diethylstilbetrol in Max-Plank-Institut für Hirnforschung (Cologne, Germany). Tumors in Cases 2 through 7 were induced in the brain of SD-JCL rats by a single intraperitoneal injection of $50 \mathrm{mg} / \mathrm{kg}$ of ENU on the 17th day of gestation in our laboratory.

Two clones (RGL-1.1 and 2.1) were estab-
Table 1 Original tumors prepared for chromosome analysis

\begin{tabular}{|c|c|}
\hline Case No. & Histological diagnosis \\
\hline 1. & isomorphous ependymoma* \\
\hline 2. & polymorphous oligodendroglioma \\
\hline 3. & olfactory bulb tumor \\
\hline 4. & polymorphous oligodendroglioma \\
\hline 5. & polymorphous mixed glioma \\
\hline 6. & polymorphous mixed glioma \\
\hline 7. & polymorphous ependymoma \\
\hline
\end{tabular}

*Given from Max-Plank-Institute für Hirnforschung, Cologne, West-Germany.

lished at the initial stage of cell culture and karyotypes of both clones until the 38th passage (360 days in vitro) were reported in another publication. ${ }^{11)}$ Both clonal cells showed the subdiploid modal chromosome number until the 38th passage. Thereafter RGL 1.1 tended to present the instability of the chromosome number and on the 630th day in vitro the cells retained a main mode at the subtetraploid number without a peak near diploid. While, RGL 2.1 constantly showed the stability in chromosome number and still showed a main peak at 41 chromosome number. Cells from the tumor in Case 2 showed a round oligodendroglial form in vitro at the initial stage. After the 10th passage, the cultured cells presented two different patterns; astrocytic and oligodendroglial forms, therefore, single cell culture with cover slip method was performed. Both cell lines (Case 2-1 and Case 2-2) still retained the similar mode at subdiploid number. Case $2-1$ line gradually tended to show lower percentage of diploid or subdiploid cells than Case 2-2 line. On the 250th day in vitro, almost all cells in Case 2-1 line showed a main mode at subtetraploid number, but cells in Case $2-2$ line still showed a stable main mode at 38 chromosome number.

In Cases 3, 4, 5, and 6, no sigle cell culture was performed. In these 4 cases, chromosome analysis was made at intervals between $20-60$ days in vitro, for the comparison with long termed cultured cells such as Cases 1 and 2. In these cases, the cells showed main distribution peaks at 40-42 chromosomes, with wide spread of the chromosome counts from the subdiploid to subtetraploid range, and the percentage of cells 
Table 2 Chromosome counts per cell in 50 cells in tissue culture from 7 rat brain tumors

Chromosome No. Distribution

Case No. Days in culture $35,36,37,38,39,40,41,42,43,44,45-60,61-70,71-80$

$\begin{array}{lrrrrrrrrrrrrrr}1(\text { RGL 1.1) } & 630 & 0 & 0 & 0 & 0 & 0 & 0 & 0 & 1 & 1 & 0 & 1 & 4 & 43 \\ 1(\text { RGL 2.1) } & 630 & 0 & 0 & 0 & 0 & 1 & 5 & 10 & 27 & 2 & 0 & 0 & 0 & 5 \\ 2(2-1) & 250 & 0 & 0 & 0 & 0 & 0 & 0 & 0 & 0 & 0 & 0 & 3 & 20 & 27 \\ 2(2-2) & 250 & 14 & 4 & 5 & 16 & 3 & 5 & 0 & 0 & 0 & 0 & 1 & 0 & 2 \\ 3 & 56 & 7 & 3 & 2 & 1 & 2 & 7 & 10 & 12 & 4 & 1 & 1 & 0 & 0 \\ 4 & 45 & 4 & 4 & 3 & 5 & 2 & 7 & 11 & 8 & 2 & 2 & 2 & 0 & 0 \\ 5 & 40 & 2 & 2 & 0 & 4 & 5 & 8 & 11 & 13 & 3 & 0 & 0 & 0 & 2 \\ 6 & 20 & 6 & 4 & 1 & 3 & 3 & 9 & 10 & 9 & 3 & 0 & 0 & 0 & 0 \\ 7 & 4 & 8 & 3 & 3 & 7 & 5 & 5 & 6 & 7 & 1 & 0 & 1 & 0 & 4\end{array}$

which presented modal chromosome number was lower than that of the cells in Cases 1 and 2. Case 7 was karyotypically analysed on the 4 th day in vitro at the initial culture. No main modal distribution was observed at this stage.

Chromosome distributions in the 7 rat glial tumors were summarized in Table 2.

B) Peculiar karyotypes and the appearance of marker chromosomes.

The 7 rat glial tumors were karyotypically analysed in cells which presented modal chromosome number and these cells were interpreted as representative ones of the tumors. The other cells which presented no modal num- ber were not karyotyped because these cells contained many random chromosome missings.

Table 3 shows a summary of the karyotypes of the 7 rat glial tumors which presented the diploid or subdiploid chromosome number, and subtetraploid group (RGL 1.1 and Case 2-1) are not described in this table.

RGL 2-1 cells in Case 1 showed subdiploid modal number of 41 chromosomes, one \#3 chromosome missing and one additional large metacentric marker chromosome (Fig. 2A). Gband (Fig. 2B) showed no similarity between \#3 chromosome and the marker, therefore, disappearance of one \#3 chromosome was not re-

Table 3 Summary of Karyotypes from 7 rat glial tumors (Presented as deviation from the diploid number for each group)

\begin{tabular}{|c|c|c|c|c|c|c|c|c|c|c|c|}
\hline \multirow[b]{2}{*}{ Case No. } & \multirow[b]{2}{*}{ Cell } & \multirow{2}{*}{$\begin{array}{c}\text { Chromosome } \\
\text { No. }\end{array}$} & \multicolumn{9}{|c|}{ Chromosome number and group } \\
\hline & & & 1 , & 2 & 3 & $4-X-10$ & 11 & 12 & 13 & 14-20, Y, & Marker \\
\hline \multirow[t]{2}{*}{1 (RGL 2.1) } & 1 & 42 & & & -1 & & & & & & +1 \\
\hline & 2 & 42 & & & -1 & & & & & & +1 \\
\hline \multirow[t]{2}{*}{2 (Case 2-2) } & 1 & 39 & & -1 & -1 & & -1 & & & -2 & +2 \\
\hline & 2 & 42 & & & -1 & -1 & & & & & +2 \\
\hline \multirow[t]{2}{*}{3} & 1 & 40 & & & -1 & -1 & +1 & & & -1 & \\
\hline & 2 & 42 & & & -1 & & +1 & & & & \\
\hline \multirow[t]{2}{*}{4} & $\overline{1}$ & 45 & +1 & & & +1 & +1 & +1 & & & \\
\hline & 2 & 42 & +1 & & & +1 & +2 & & & -3 & \\
\hline \multirow[t]{2}{*}{5} & 1 & 38 & & -1 & -1 & -1 & & & & -1 & \\
\hline & 2 & 38 & & & -1 & -2 & & & & -1 & \\
\hline \multirow[t]{2}{*}{6} & 1 & 42 & & & -1 & & +1 & +1 & & -1 & \\
\hline & 2 & 42 & & & -1 & & +1 & & & & \\
\hline \multirow[t]{2}{*}{7} & 1 & 41 & & -1 & & & & & & & \\
\hline & 2 & 41 & & & & & +1 & & & -2 & \\
\hline
\end{tabular}




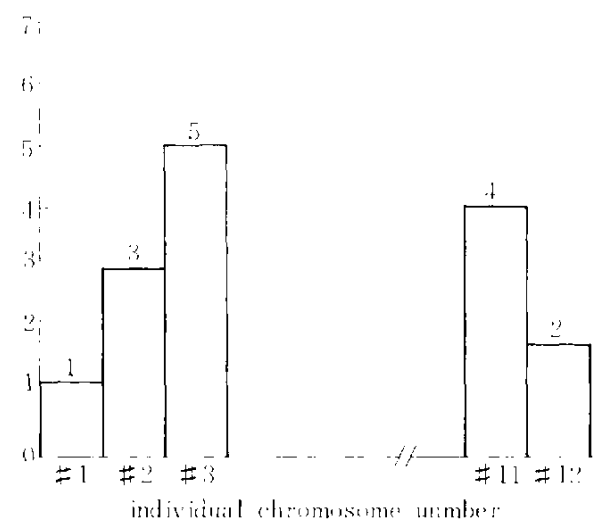

Fig. 1 The incidence of chromosome abnormality in 7 ral glial tumors in vitro. Abnormality in \#2 and 3 chromosomes shows monosomy. Abnormality in $\# 1,11$ and 12 chromosomes shows trisomy. Aberrations in T-group (4-X-10) and M-group (14-20) are not presented in this figure.

\section{II $\ln _{-3-2}$ an 19 in

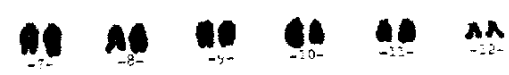

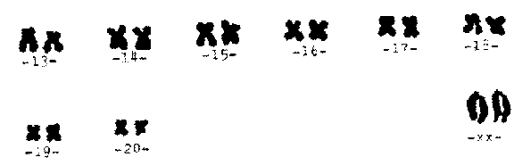

Fig. 2A Karyotype of Case 1 (RGL 2, 1) shows 42 chromosomes, with one \# 3 chromosome monosomy and appearance of a marker chromosome.

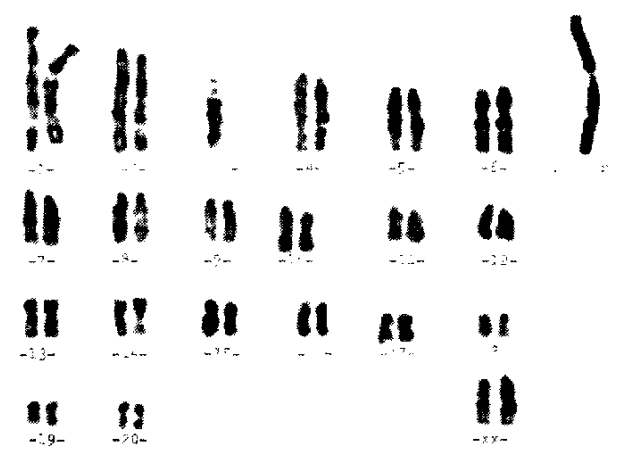

Fig. 2B. G-band karyotype of Case 1 shows no relation between \# 3 chromosomes and the marker. lated to the additional metacentric marker. Karyotype of Case 2-2 consisted of one \#3 chromosome constantly missing, one \#2 chromosome occasionally missing, one chromosome disappearance in T-group (\#4-X-11) and the appearance of the two markers; large metacentric and submetacentric ones (Fig. 2C). Cells from Case 3 showed one \# 3 chromosome missing and one additional chromosome in \#11 or 12 chromosomes. No markers were observed (Fig. 2D).

Karyotype of Case 4 presented a different figure; no monosomy for \# 3 chromosomes was present. One additional chromosome for \#1,10, 11 , and 12 chromosomes was observed (Fig. 2E). Case 5 showed monosomy for \#3 chromosomes, one \#2 chromosome occasionally missing and one or two chromosomes missing in $\mathrm{T}$ group (\#4-X-11) (Fig. 2F). Karyotype of Case 6 was composed of consistent monosomy for \# 3 chromosomes and occasional appearance of one

\section{i) II I II II II

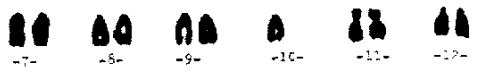

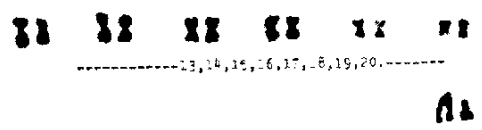

Fig. 2C. Karyotype of Case 2-2. Complete \#3 monosomy, missing of one chromosome from $\mathrm{T}$ group and appearance of two markers are present.

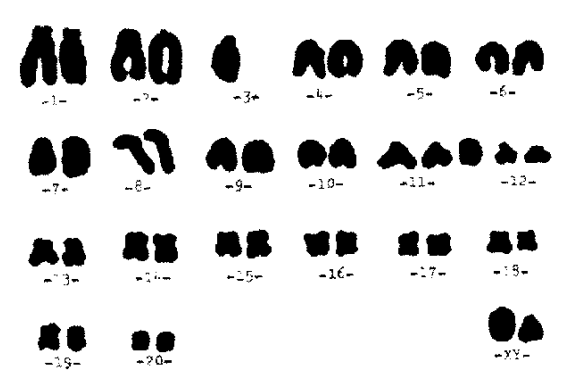

Fig. 2D. Karyotype of Case 3. One \#3 chromosome missing and one additional chromosome belonging to \#10,11 or 12 chromosomes are observed. 


\section{If 10 if 14 a
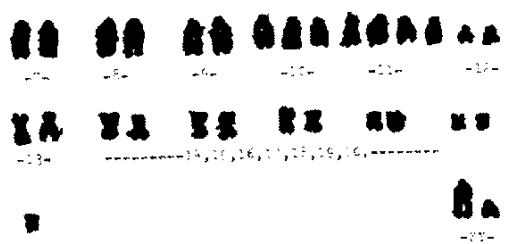

Fig. 2E. Karyotype of Case 4. One additional chromosome for \#1,10,11, and 12 chromosomes are frequently seen.

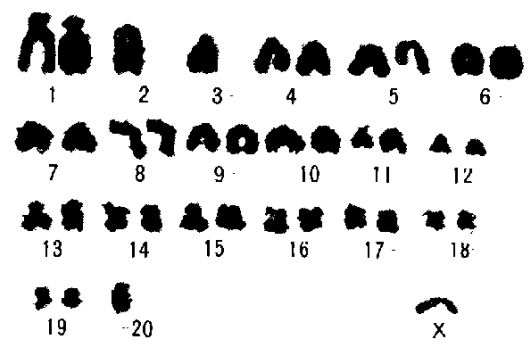

Fig. 2F. Karyotype of Case 5. Monosomy for \#2 and 3 chromosomes is present.

chromosome in \# 11 and 12 chromosomes in addition (Fig. 3A). Case 7 was karyotyped at the 1st passage and showed a large variance of chromosome number near the diploid. In karyotyped cells, no \#3 chromosome missing was observed. One \#2 chromosome missing and one additional chromosome in \#11 chromosomes were occasionally observed (Fig. 3B).

Case 1 showed no chromosome missing in $\mathrm{M}$ group (\# 14-20), while Cases 2 through 7 always showed two or three chromosome missing in M-group. Those missing were not discussed because the missing ones for individual chromosome number could not be identified. These chromosomal missings were only summarized in Table 3. Through 7 cases, karyotypic abnormality was preferentially observed in $\# 2,3,11$ and 12 chromosomes. The incidence of the abnormality in these chromosomes are shown in Fig. 1.

Monosomy for \#3 was predominantly present in 5 cases out of 7 and \#2 monosomy was seen in 3 cases. Trisomy for \#1, 11, and 12 chromosomes was present, but one additional chromosome in \#11 and 12 chromosomes fre-

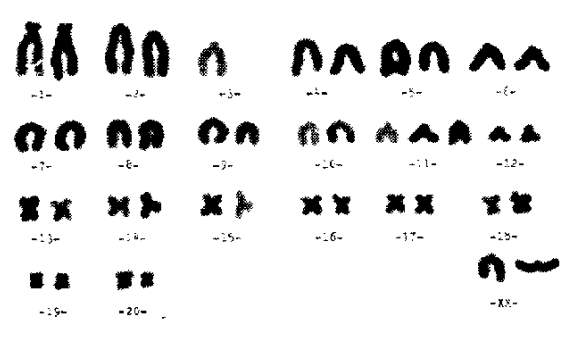

Fig. 3A. Karyotype of Case 6. \#3 monosomy and one extra chromosome belonging to $\mathrm{T}$ group are observed.

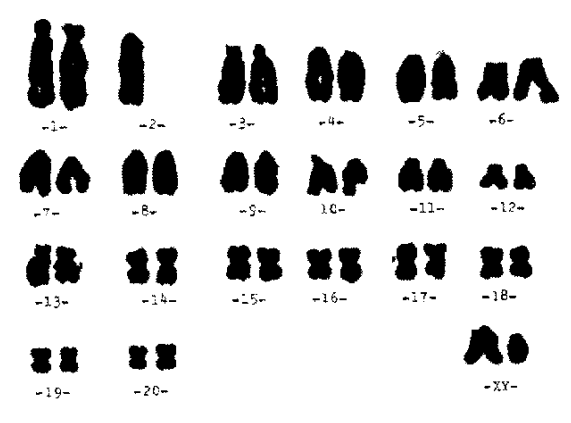

Fig. 3B. Karyotype of Case 7. One \# 2 chromosome missing and one additional chromosome in \#11 chromosomes are observed.

quently showed a slight morphological change.

\section{Discussion}

The results of our investigation showed that chromosome aberrations in cells on the rat glial tumors induced by repeated injections of MNU and a transplacental administration of ENU were composed of complete monosomy for \#3 chromosomes and partial monosomy for \#2 chromosomes. In addition, histological classification of experimental rat glial tumors had no relation with the consistent chromosome abnormality.

In the experiments performed by Fujiwara, ${ }^{2)}$ cells from fetal brain tissue shortly after a transplacental administration of ENU showed preferential chromosome damages (breaks and gaps) in \# 1 and 2 chromosomes (Figs. $3 \mathrm{C}$ and 3D). \#3 chromosomes were less frequently damaged in this experiments.

These damages shortly after ENU adminis- 


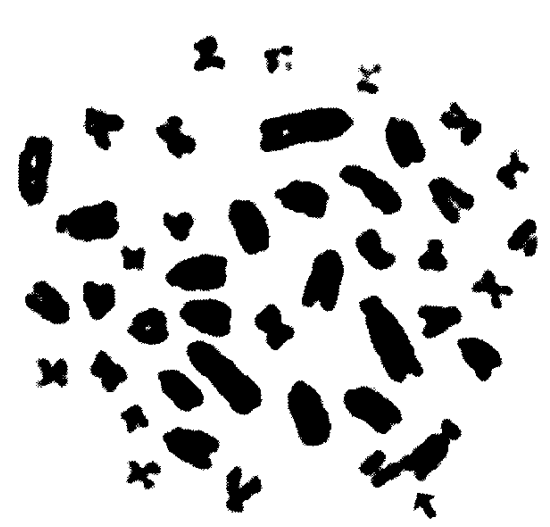

$\mathrm{C}$

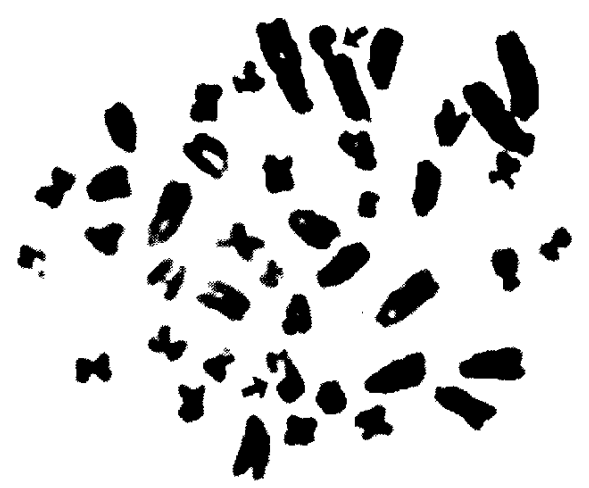

$\mathrm{D}$

Fig. 3C. and 3D. Figure 3C shows break (arrow) in \#1 chromosome and figure 3D reveals distinctive gaps (arrows) of \#2 and one another chromosome belonging to $T$ group (these changes were demonstrated in the experiments carried out by Fujiwara $^{2)}$ ).

tration appear to be almost the same as ones occurring in bone marrow cells of rats shortly after an intravenous administration of chemical carcinogens and interpreted as toxical changes by chemical carcinogens. ${ }^{17}$

The mechanism of selective carcinogenic action of the nitroso compounds in the nervous system was not yet clarified.

Magee $^{7,8)}$ tried to correlate biological significance of nucleic acid alkylation at the 7position of guanine with a carcinogenic transformation, but the same alkylation was observed in both neuronal and glial cells in the rat brains.

Kleihues ${ }^{5)}$ concluded that the failure to develop neuronal tumors in rats treated with the nitroso compounds might be related to the lack of proliferating capacity of the neuronal cells, because no difference was observed between the extent of the initial interaction of the nitroso carcinogen with the neuronal and the glial cells.

The question whether the carcinogenic action of DNA alkylation means an increased proliferative acitivity due to the change of proliferation mechanism or an autonomous cell growth due to the damage of suppressor mechanism, however, remains unanswered, if chemical carcinogenecity means a change in the control mechanism for cell replication. If these alkylating agents showed the destruction of the genetical cell control mechanism for cell replication, such modified information must be permanently present in cells which show unlimited proliteration later in life, and be transmitted to tumor cells as a consistent defect of some genetical information.

From this point of view, we tried to investigate the possibility of common chromosome destruction in cells from the rat glial tumors induced by MNU and ENU, because chromosomal change is one indicator of the underlying abnormality in the genetical information.

Many reports on chromosome abnormality in leukemia ${ }^{6.19)}$ and hepatoma ${ }^{14.18)}$ of rats induced by chemical carcinogens showed preferential involvement of \#1,2, and 3 chromosomes in numerical and morphological alterations. Chromosomes \#1 and 2 are considered to be direct target ones which are toxically injured by chemical carcinogens, because these chromosomes show an easy destrucion shortly after the administration of carcinogen. ${ }^{15,17)}$ In the experiments of chromosome analysis in fetal brain cells shortly after ENU administration, \#1 and 2 chromosome showed preferentially breaks and gaps and \# 3 chromosomes were less frequently damaged. These changes appear to be caused by toxical effect of ENU.

Neoplastic glial cells in Cases 1 and 2 showed one \# 3 chromosome missing and additional marker chromosomes. Thust ${ }^{21)}$ showed absence of single chromosome with simultaneous occurence of marker chromosome in spinal sarco- 
matous tumor induced by MNU. In our cases, however, G-band ${ }^{1)}$ showed no relation of one \#3 chromosome missing with the occurence of the marker. The other 5 cases showed complete \# 3 monosomy or partial \#2 monosomy without associating marker chromosomes.

Cells from 6 rat glial tumors induced by ENU commonly presented involvement of \#11 and 12 chromosomes in numerical and in morphological alterations. No interpretation for these alterations was made.

We turned our attention to the low incidence of \#3 chromosome damage of fetal brain cells shortly after ENU administration and discovered surprisingly high incidences of \# 3 monosomy in cells of rat glial tumors induced by the nitroso carcinogen.

These glial neoplastic cells showed selectively active proliferation in vitro and aggressive tumor growth in vivo. We have no data about chromosome constitution of pre-existing malignant cells before the appearance of microtumor induced by the nitroso carcinogen.

The question whether the alkylation caused by the transplacental effect of ENU on the stage of embryogenesis of rats is related to only \#3 chromosomes or also to \#1,2, and 3 chromosomes is still unresolved. We hypothetically consider that \#3 chromosome damage appears to be responsible for the permanent genetical changes into neoplastic glial cells from normal glial ones and that these transformed cells develop autonomous proliferation because of the lack of the cell control mechanism.

Some reports on chromosome analysis of neurogenic tumors of rats induced by nitroso compounds did not demonstrate universal chromosome changes. ${ }^{10,16,21)}$ Many investigat ors demonstrated numerical and structural chromosome aberrations, preferentially involving \#1,2, or 3 chromosomes in leukemia, ${ }^{6.191}$ lymphosarcoma $^{13)}$ fibrosarcoma ${ }^{15)}$ and hepatoma ${ }^{24)}$ of rats induced by chemical carcinogen. Nevertheless, the problem whether these common abnormalities are causatively related to carcinogenic transformation remains unresolved, because the genetical changes at the molecular level cannot be detected with chromosome analysis.

\section{Acknowlegement}

The authors express cordial thanks to Dr. H.
D. Mennel, Max-Plank-Institut für Hirnforschung, Cologne, Germany, for his guidance at the beginning of this study. RGL 1.1 and 2.1 clonal cells were given from the institute.

\section{References}

1) Commette for a standardized karyotype of Rattus norvegicus.: Standard karyotype of the norway rat, Rattus norvegicus. Cytogenet. Cell. Genet. 12: 199-205, 1973

2) Fujiwara, K., Tanaka, M., Taomoto, K., Tamaki, N., Matsumoto, S. and Sugiyama, T.: Chromosome abnormality in the cells of fetal $r$ at brains and rat brain tumors induced by a transplacental administration of ENU., Proceedings of the 17th Ann. Meet. Japan Neurol. Soc., Tokyo, 1976

3) Goth, R. and Rajewsky, M. F.: Ethylation of nucleic acids by ethylnitrosourea- $1 .{ }^{14} \mathrm{C}$ in the fetal and adult rats. Cancer Res. 32: 1501-1505, 1972

4) Kleihues, P., Matsumoto, S., Wechsler, W. and Zulch, K. J.: Morphologie und Wachstum der Athylnitrosoharnstoff transplazentar erzeugten Tumoren des Nervensystems. Verh. Disch. Ges. Path. 52: 372-379, 1968

5) Kleihues, P., Magee, P. N., Cox, J. A. D. and Mathias, A. P.: Reaction of N-methyl-Nnitrosourea with DNA of neuronal and glial cells in vivo. Febs Letters 32: 105-108, 1973

6) Kurita, Y., Sugiyama, T. and Nishizuka, Y.: Cytogenic studies on rat leukemia induced by pulse doses of 7, 12-Dimethylbenz $(x)$ anthracene. Cancer Res. 28: 1738-1752, 1968

7) Magee, P. N. : In vivo reactions of nitroso compounds. Ann. N. Y. Acad. Sci. 168: 717-730, 1969

8) Magee, P. N. : Mechanism of transplacental carcinogenesis by nitroso compounds., Transplacental carcinogenesis, IARC Scientific Publications No. 4, IARC, Lyon, 1973

9) Mennel, H. D. and Zülch, K. J.: Formale Pathogeness expperimentelle Hirntumoren. Acta neuropath. 21: 140-153, 1972

10) Mennel, H. D. and Bücheler, J.: Experimentally induced malignant neurinomas as transplantable tumors. Acta neuropath. 27: 153-161, 1974

11) Mennel, H. D., Tanaka, M. and Braun, M.: In vitro growth of neoplastic rat glial cells. $Z$. Krebsforsch. 84: 193-202, 1975

12) Mennel, H. D.: Experimental tumors of the nervous system. Recent Results in Cancer Research. Springer-Verlag, 44: 158-169, 1974

13) Mori, M. and Sasaki, M.: Chromosome studies on rat leukemias and lymphomas, with special 
attention to fluorescent karyotype analysis. $J$. Natl. Cancer Inst. 52: 153-160, 1974

14) Nowell, P. C.: Morris, H. P. and Potters, V.: Chromosomes of "Minimal deviation" hepatoma and some other transplantable tumors. Cancer Res. 27 : 1565-1579, 1967

15) Olinici, C. D. and Dipaolo, J. A.: Chromosome banding patterns of rat fibrosarcoma induced by in vitro transformation of embryo cells or in vivo injection of rats 7, 12-dimethylbenzanthracene. J. Natl. Cancer In.st. 52: 1627-1634, 1974

16) Pfeiffer, S. E. and Wechsler, W.: Biochemically differentiated clone of schwann cells. Proc. Nat. Acad. Sci. 69: 2884-2889, 1972

17) Rees, E. D., Majundar, S. K. and Shuck, A. : Changes in chromosomes of bone marrow after intravenous injection of 7, 12-dimethylbenzanthracene and related compounds. Proc. Natl. Acad. Sci. 66: 1228-1235, 1970

18) Sell, S. and Morris, H. P.: Relation of rat-fetoprotien to growth rate and chromosome compositon of Morris hepatoma. Cancer Res. 34: 1413-1417, 1974

19) Sugiyama, T., Kurita, Y. and Nishizuka, Y.: Chromosome abnormality in rat leukemia induced by 7, 12-dimethylbenz $(\alpha)$ anthracene.
Science 158: 1058-1059, 1967

20) Sumner, A. T., Evans, H. J. and Buckland, R. A. : New technique for distinguishing between human chromosomes. Nature New Biol. 232: 31-32, 1971

21) Thust, R.: Karyotypverynderungen in Klonen eines N-Methylnitrosoharnstoff induzierten euploiden Sarkoms des Rückenmarks der Ratten in vitro. Exp. Path. 5: 226-234, 1971

22) Wechsler, W., Kleihues, P., Matsumoto, S. and Zülch, K. J. : Pathology of experimental neurogenic tumors chemically induced during prenatal and postnatal life. Ann. N. Y. Acad. Sci. 159 : 360-408, 1969

23) Wechsler, W.: Careinogenic and teratogenic effects of ethylnitrosourea and methylnitrosourea during in experimental rats. Transplacental carcinogenesis, IARC Scientific Publications. No. 4, IARC, p. 127-142 Lyon, 1973

24) Wolman, S. R., Horland, A. and Becker, F. F.: Altered karyotypes of transplantable "diploid" tumors. J. Natl. Cancer Inst. 51: 1909-1914, 1973

25) Zülch, K. J. and Mennel, H. D.: Die Morphologie der durch alkylierende Substanzen erzeugten Tumoren. Zhl. Neurochirurg. 32: 225-243, 1971 